\title{
O ensino de Língua Inglesa na rede federal de ensino técnico e tecnológico: práticas pedagógicas ativas baseadas na pedagogia por projetos e no ensino híbrido com abordagem para fins específicos no Instituto Federal do Paraná - Campus Jaguariaíva
}

Ramon Martins ${ }^{1}$

\begin{abstract}
Resumo
A presente narrativa tem como objetivo relatar como se realizou um trabalho em sala de aula com base metodológica na pedagogia por projetos e no ensino híbrido, ainda com foco em fins específicos e no letramento para o mundo do trabalho. O trabalho narrado aconteceu no Instituto Federal do Paraná - Campus Jaguariaíva, no ano de 2019, em uma turma de terceiro ano do Ensino Médio Integrado à Biotecnologia. A atividade abordou o uso dos currículos vitae, quais são as características desses, seus aspectos como gênero textual, as particularidades acerca dos diversos tipos de currículos e como se deu a construção desses por parte dos alunos. Esta narrativa também levanta aspectos teóricos do trabalho e da organização docente bem como de aspectos burocráticos que normatizam a prática pedagógica docente e discente. Apresentam-se também exemplos de produtos finais construídos pelos alunos, bem como uma discussão entre as tensões encontradas no caminho trilhado e acerca das entrelinhas do trabalho educacional.
\end{abstract}

Palavras-chave: Ensino de língua inglesa. Pedagogia por Projetos. Inglês para Fins Específicos.

Abstract

The present narrative aims to report how a work in the classroom with methodological basis was carried out in project pedagogy and blended learning, still focusing on specific purposes and literacy for the world of work. The narrated work took place at the Federal Institute of Paraná - Campus Jaguariaiva in 2019 in a third-year class from High School Integrated to Biotechnology. The activity addressed the use of resume, what are the characteristics of these, their aspects as textual genre, the particularities about the different types of resume and how the construction of these by the students took place. This narrative also raises theoretical aspects of the work and the teaching organization, as well as bureaucratic aspects that guide the teacher and student pedagogical practice. Examples of final products built by the students are also presented, as well as a discussion among the tensions found along the path and about the between the lines of educational work.

Keywords: English language teaching. Pedagogy of Projects. English for Specific Purposes.

\section{Apresentação}

Ano a ano, antes do início do calendário acadêmico, é normal o corpo docente de uma instituição de ensino se reunir para propor situações pedagógicas a se desenrolarem durante o período letivo. Chamam-se de reuniões pedagógicas, encontros de formação, dentre outras nomeações, estes momentos para planejamento do trabalho pedagógico. Muito se observa acerca destes planejamentos, pois antes de mais nada, esses apresentam o modo de ver, sentir, prever, avaliar do educador e dificilmente conta com a presença da visão do corpo

\footnotetext{
${ }_{1}^{1}$ Mestre em Educação. Instituto Federal do Paraná. E-mail: ramon.martins@ifpr.edu.br.
} 
discente, e por isso, por vezes, o educador pode vir a sentir a necessidade de expor este plano aos educandos. Assim, aquele pode ser construído visando uma educação para os alunos ou pode também ser direcionados a um processo com os alunos (FREIRE, 1989).

Sendo assim, este relato apresentará um processo pedagógico que tentou em sua predominância ser uma ação construída com os estudantes... e não para os estudantes. É uma afirmação categórica dizer que estes processos construídos não só por professores são escassos, mas a formatação administrativa de nossa educação a predispõe aos processos de desenvolvimento de maneira bancária (FREIRE, 1989) muito mais que ativa² para execução da prática educacional.

Por vezes, os educadores usam de seu capital cultural, intelectual e técnico para construir planos de ensino que serão aplicados aos estudantes, promovendo assim um processo de mão única, pois os esses não participam da construção de seu planejamento educacional. A tradicional escola talvez nem permita, não apenas no sentido administrativo, mas também no sentido intelectual, que os estudantes participem dos planejamentos dos processos, pois é natural que os educandos fiquem na expectativa do que o professor thes trará. Assim, este relato apresentará uma proposta que teve início na tentativa de um trabalho dialógico, que visava à realidade concreta dos envolvidos (FREIRE, 1989).

\section{Contexto acerca do trabalho executado}

A proposta aqui a ser relatada aconteceu no Instituto Federal do Paraná - Campus Jaguariaíva em uma turma de 38 alunos de um curso de Ensino Médio Integrado à Biotecnologia no ano de 2019, curso esse com duração de 4 anos. Quanto ao educador, esse vem de uma estrada de mais de 15 anos na educação, executou propostas na rede privada e está há 5 anos da Rede Federal de Educação Técnica e Tecnológica. Para além, cabe mencionar que no início desta prática narrada aqui, o docente tinha voltado de afastamento para conclusão de curso stricto sensu em Educação, na linha de Teoria e Práticas da Educação, logo teve que considerar todo o trabalho já realizado pelo profissional que

\footnotetext{
${ }^{2}$ Acerca de pedagogias ativas de aprendizagem, há um número considerável de conceitos e autores, a exemplos Ventura (2002), com a Pedagogia por Projetos; Moran (2015), com o Ensino Híbrido. Não serão elencadas mais teorias aqui devido estas duas práticas mencionadas serem as que fundamentaram as práticas neste texto narradas.
} 
lecionava anteriormente na turma e também levar em conta a aquisição de conhecimentos do corpo discente.

Vale-se levantar que o Projeto Pedagógico de Curso sofreu uma revisão durante este tempo e realizaram-se algumas sugestões oriundas da Pró-reitoria de Ensino da instituição. Essa alertou para a necessidade de várias alterações protocolares, como predeterminação de ementa (na verdade elencando conteúdos), determinação de carga horária exata de execução das aulas e várias outras mudanças mesmo após o PPC já ter sido aprovado.

É interessante aqui pautar como era o primeiro PPC aprovado e como veio a se formar o projeto que se executa até hoje.

No primeiro PPC, constavam para o terceiro ano 500 horas destinadas o Núcleo Comum, ou seja, para as disciplinas tratadas como propedêuticas. Destas horas, a estrutura modular absorvia o tempo de trabalho com uma proposta interdisciplinar, assim um planejamento prévio sobre projetos de ensino era necessário para dar início ao trabalho e deveria ser construído em conjunto pelos educadores (este trabalho era necessário principalmente pelo caráter interdisciplinar do projeto, não prevendo a construção de práticas predominantemente individuais). A tabela abaixo apresenta a situação referente a turma supracitada.

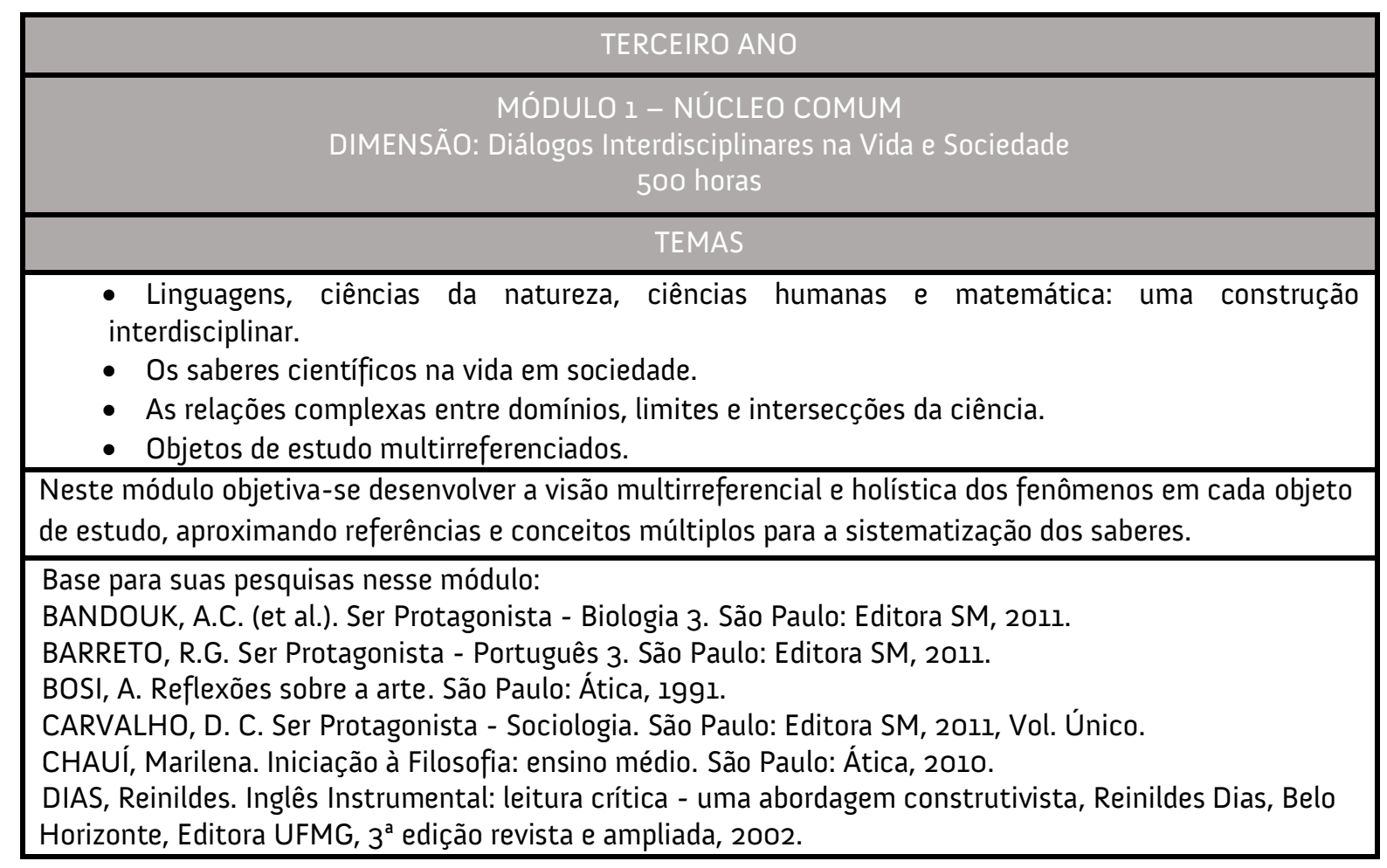


FUGUITA, F. (et al.) Ser Protagonista - Matemática 3. São Paulo: Editora SM, 2011.

FUKUI, A. (et al.) Ser Protagonista - Física 3. São Paulo: Editora SM, 2011.

KUNZ, E. Educação Física: ensino e mudanças. Ijuí: Unijuí, 1991.

LISBOA, J.C.F. Ser Protagonista - Química 3. São Paulo: Editora SM, 2011.

NOGUEIRA, F.H.G.; CAPELLARI, M.A. Ser Protagonista - História. São Paulo: Editora SM, 2011, Vol. Único.

RAMOS, R. de A.; STEFANOVITS, A. Ser Protagonista - Gramática. São Paulo: Editora SM, 2011, Vol.

Único.

SAMPAIO, F. dos S.; SUCENA, I.S. Ser Protagonista - Geografia. São Paulo: Editora SM, 2011, Vol. Único.

VILLALBA, T.K.B (et al.) El Arte de Leer Español 3. São Paulo: Base Editorial, 2011.

Complementos para sua pesquisa:

BASSANEZI, R. C. Ensino-aprendizagem com modelagem matemática: uma nova estratégia. São Paulo: Contexto, 2002.

CARVALHO, C (et al.). Quuímica de Olho no mundo do Trabalho. São Paulo: Editora Scipione, 2004, Vol. Único.

GASPAR, A. Compreendendo a Física. São Paulo: Editora Ática, 2011, Vol. 2.

GASPAR, A. Física - Série Brasil volume único. São Paulo: Editora Ática, 1994.

MATTOS, N.S. de; PEZZI, A.C. Biologia - Volume único - Ensino Médio - Integrado. São Paulo: FTD -

Didáticos, 2010.

Tabela 1. Quadro demonstrativo - Projeto Pedagógico de Curso.

Fonte: INSTITUTO FEDERAL DO PARANÁ. Projeto Pedagógico do Curso Técnico em Biotecnologia Integrado ao Ensino Médio - Campus Jaguariaíva. 2014.

Ao analisar o conteúdo do projeto para o terceiro ano, percebe-se que as disciplinas não se encontram nesta parte do texto, mas sim as dimensões do conhecimento. Neste módulo, encontra-se a dimensão Linguagens e isso leva a subentender que a Língua Estrangeira se encontra neste módulo. Não cabe neste relato a maneira que se concretizou este PPC, mas vê-se que era uma proposta baseada na interdisciplinaridade e que a multirreferencialidade (ARDOINO, 1998) era o mote de execução do plano ${ }^{3}$.

Após a revisão do projeto pedagógico ${ }^{4}$, encontra-se a matriz curricular abaixo.

\footnotetext{
3 Para aprofundar-se no conhecimento do PPC, visitar https://www.acervodigital.ufpr.br/bitstream/handle/1884/58150/R\%20-\%20D\%20\%20RAMON\%20MARTINS.pdf? sequence =18isAllowed $=y$.

4 Disponível em https://jaguariaiva.ifpr.edu.br/wp-content/uploads/2019/02/Curso-T\%c3\%agcnico-emBiotecnologia-integrado-ao-Ensino-M\%c3\%agdio-\%c3\%baltima-vers\%c3\%a3o.pdf.
} 


\begin{tabular}{|c|c|c|c|c|c|c|c|c|}
\hline \multicolumn{9}{|c|}{$\begin{array}{l}\text { Matriz curricular do Curso Técnico em Biotecnologia } \\
\text { integrado ao ensino médio }\end{array}$} \\
\hline \multicolumn{9}{|c|}{ Ano de implantação: 2018} \\
\hline \multicolumn{2}{|c|}{ Componente Curricular } & $\begin{array}{l}1^{0} \\
\text { ano } \\
(\mathrm{h} / \mathrm{r})\end{array}$ & $\begin{array}{l}2^{0} \\
\text { ano } \\
(\mathrm{h} / \mathrm{r})\end{array}$ & $\begin{array}{c}3^{\circ} \\
\text { ano } \\
(\mathrm{h} / \mathrm{r})\end{array}$ & $\begin{array}{l}4^{\circ} \\
\text { ano } \\
(\mathrm{h} / \mathrm{r})\end{array}$ & $\begin{array}{l}N^{0} \text { aula } \\
\text { semanal } \\
\text { (50 min) }\end{array}$ & $\begin{array}{c}\text { Total } \\
\text { Hora- } \\
\text { aula }\end{array}$ & $\begin{array}{c}\text { Total } \\
\text { Hora } \\
\text { relógio }\end{array}$ \\
\hline \multirow{13}{*}{ 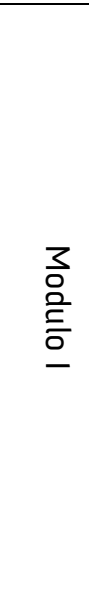 } & $\begin{array}{l}\text { Língua Portuguesa e } \\
\text { Literaturas }\end{array}$ & 134 & 100 & 100 & 134 & $4,3,3,4$ & 560 & 468 \\
\hline & História & 67 & 67 & 33 & 33 & $2,2,1,1$ & 240 & 200 \\
\hline & Filosofia & 33 & 33 & 33 & 33 & $1,1,1,1$ & 160 & 132 \\
\hline & Sociologia & 33 & 33 & 33 & 33 & $1,1,1,1$ & 160 & 132 \\
\hline & Inglês & 66 & 67 & 33 & 33 & $2,2,1,1$ & 240 & 199 \\
\hline & Espanhol & 67 & 33 & 33 & 33 & $2,2,1,1$ & 240 & 166 \\
\hline & Educação Física & 33 & 67 & & & 1,2 & 120 & 100 \\
\hline & Arte & 100 & 33 & & & 2,1 & 120 & 133 \\
\hline & Matemática & & 67 & 67 & 100 & $2,2,3$ & 280 & 234 \\
\hline & Química & & & 67 & 67 & 2,2 & 160 & 134 \\
\hline & Biologia & & & 67 & 67 & 2,2 & 160 & 134 \\
\hline & Física & & & 67 & 67 & 2,2 & 80 & 134 \\
\hline & Geografia & & & 67 & & 2,2 & 80 & 67 \\
\hline \multirow{18}{*}{$\begin{array}{l}\frac{3}{\circ} \\
\stackrel{0}{0} \\
\stackrel{0}{=}\end{array}$} & Geografia & 67 & 67 & & & 2,2 & 160 & 134 \\
\hline & Biologia & 67 & 67 & & & 2,3 & 200 & 134 \\
\hline & Física & 67 & 100 & & & 2,3 & 200 & 167 \\
\hline & $\begin{array}{l}\text { Química ( fund. Prát. } \\
\text { Laboratoriais }\end{array}$ & 66 & 100 & & & 2,3 & 200 & 166 \\
\hline & Matemática & 100 & 33 & & & 3,1 & 240 & 133 \\
\hline & Redação para a Bitecnologia & & 33 & & & 1 & 40 & 33 \\
\hline & Biotec. na prod. de Alimentos & & & 67 & & 2 & 80 & 67 \\
\hline & $\begin{array}{l}\text { Biotec. prod. de Biofarm. e } \\
\text { Biodef. }\end{array}$ & & & 67 & & 2 & 80 & 67 \\
\hline & O Meio Ambiente e a Biotec. & & & 33 & & 1 & 40 & 33 \\
\hline & $\begin{array}{l}\text { Controle Qual. Físico-Quuímico } \\
\text { Bioprod }\end{array}$ & & & 66 & & 2 & 80 & 66 \\
\hline & $\begin{array}{l}\text { Controle de Qual. Microbiol. } \\
\text { Bioprodu. }\end{array}$ & & & 67 & & 2 & 80 & 67 \\
\hline & $\begin{array}{l}\text { Proj. Meio Cons. Meio Amb. } \\
\text { Qual. Vida }\end{array}$ & & & & 67 & 2 & 80 & 67 \\
\hline & Inovação em Biotecnologia & & & & 33 & 1 & 40 & 33 \\
\hline & $\begin{array}{l}\text { O Perfil mpreendedor na } \\
\text { Biotec. }\end{array}$ & & & & 33 & 1 & 40 & 33 \\
\hline & $\begin{array}{l}\text { Valor. Circ. e Prot. Prop. } \\
\text { Intelectuais }\end{array}$ & & & & 33 & 1 & 40 & 33 \\
\hline & Probabilidades em Biotec. & & & & 67 & 2 & 80 & 67 \\
\hline & $\begin{array}{l}\text { Introdução a biologia } \\
\text { molecular }\end{array}$ & & & & 33 & 1 & 40 & 33 \\
\hline & $\begin{array}{l}\text { Informática para a } \\
\text { biotecnologia }\end{array}$ & & & & 34 & 1 & 40 & 34 \\
\hline \multicolumn{2}{|c|}{ Carga horária parcial do curso } & 900 & 900 & 900 & 900 & 900 & 4320 & 4360 \\
\hline \multicolumn{2}{|c|}{ Carga horária total do curso } & 900 & 900 & 900 & 900 & 900 & 4320 & 4360 \\
\hline
\end{tabular}

Tabela 2. Quadro demonstrativo - Projeto Pedagógico de Curso.

Fonte: INSTITUTO FEDERAL DO PARANÁ. Projeto Pedagógico do Curso Técnico em Biotecnologia Integrado ao Ensino Médio - Campus Jaguariaíva. 2017. 
Após análise do conteúdo desta matriz, percebe-se que a revisão do PPC manteve os módulos, mas direcionou um quantitativo de carga horária para cada disciplina. Fica claro que não há critério para configurar uma disciplina com mais carga horária que outra. A exemplo disso, vê-se que Língua Portuguesa e Matemática, aos moldes da cultura escolar ${ }^{5}$ tradicional, possuem cargas horárias muito acima das demais disciplinas.

Analisemos agora o quadro ${ }^{6}$ abaixo.

\begin{tabular}{|c|c|}
\hline \multicolumn{2}{|c|}{ Campus Jaguariaíva do IFPR } \\
\hline & Eixo Tecnológico: Produção Industrial \\
\hline \multicolumn{2}{|l|}{ Componente Curricular: Inglês } \\
\hline Carga Horária (hora aula): $33 \mathrm{~h}$ & Período letivo: $3^{\circ}$ ano \\
\hline \multicolumn{2}{|c|}{$\begin{array}{l}\text { Ementa: Passive voice; Reported speech; If clauses; Phrasal verbs; Idiomatic expressions; Reading Strategies: } \\
\text { interpretação de texto; Listening, speaking and writing; Wh questions and Yes/no questions; Pronomes } \\
\text { interrogativos (Wh pronouns); Entrevistas: perguntar e responder em inglês (interdisciplinaridade com Língua } \\
\text { Portuguesa e com as disciplinas técnicas). }\end{array}$} \\
\hline \multicolumn{2}{|c|}{$\begin{array}{l}\text { Bibliografia Básica: } \\
\text { DICIONÁRIO Oxford escolar: para estudantes brasileiros de inglês: português-inglês, inglês-português. 2. ed. } \\
\text { atual. New York: Oxford University Press, c2007. } 757 \text { p. } \\
\text { GREGORIM, Clóvis Osvaldo; NASH, Mark G. Michaelis: dicionário de phrasal verbs: inglês-português. 2. ed. } \\
\text { São Paulo: Melhoramentos, 2010. } 237 \text { p. (Dicionários Michaelis). } \\
\text { NASH, Mark G.; FERREIRA, Willians Ramos. Michaelis: dicionário de expressões idiomáticas: inglês-português. } \\
\text { 3. ed. São Paulo: Melhoramentos, 2010. } 249 \text { p. (Dicionários Michaelis). } \\
\text { MARTIN, Hewings. Advanced Grammar in Use. } 2 \text { edição. Cambridge:Cambridge, 2015.MCCARTHY, Michael; } \\
\text { O'DELL,Felicity. English Phrasal Verbs in Use. } 3 \text { edição. Cambridge:Cambridge, 2016. }\end{array}$} \\
\hline \multicolumn{2}{|c|}{$\begin{array}{l}\text { Bibliografia Complementar: } \\
\text { Dias R, Jucá L, Faria R. Inglês para Ensino Médio. Prime -1. } 1^{\circ} \text { ed. Editora Moderna. } \\
\text { Dias R, Jucá L, Faria R. Inglês para Ensino Médio. Prime }-2.1^{\circ} \text { ed. Editora Moderna. } \\
\text { Dias R, Jucá L, Faria R. Inglês para Ensino Médio. Prime -3. } 1^{\circ} \text { ed. Editora Moderna. } \\
\text { BAS AART, Sylvia; WEINER, Edmund. Oxford Dictionary of English Grammar. } 3 \text { edição. Oxford:Oxford, } \\
\text { 2016.RICHMOND,R. Siplified Grammar of English . 2edição. :Richmond:Moderna, } 2015 \text {. }\end{array}$} \\
\hline
\end{tabular}

Tabela 3. Quadro demonstrativo - Projeto Pedagógico de Curso.

Fonte: INSTITUTO FEDERAL DO PARANÁ. Projeto Pedagógico do Curso Técnico em Biotecnologia Integrado ao Ensino Médio - Campus Jaguariaíva. 2017.

Aqui vê-se uma caracterização de ementa, a qual nada mais se parece com um índice das primeiras páginas de uma apostila. Não cabe aqui questionar a execução daquela, nem mesmo a bibliografia proposta, muito menos a complementar, mas sim a quantidade de

\footnotetext{
${ }^{5}$ Conceito elaborado por Dominique Julia em A Cultura Escolar como Objeto Histórico. Tradução de Gizele de Souza. Disponivel em http://www.repositorio.unifesp.br/bitstream/handle/11600/39195/Dominique\%20Julia.pdf?sequence=1. Acesso em 19 de março de 2019.

6 Disponivel em https://jaguariaiva.ifpr.edu.br/wp-content/uploads/2019/02/Curso-T\%c3\%agcnico-emBiotecnologia-integrado-ao-Ensino-M\%c3\%agdio-\%c3\%baltima-vers\%c3\%a30.pdf.
} 
conteúdos em relação aos objetivos do PPC. Tal descrição não ocorrerá nesta narrativa, pois aqui não nos cabe.

O fato é que o contexto programado para a agora chamada de disciplina de Inglês possui 33 horas de aula (de 50 minutos) durante o ano letivo e este é o contexto do trabalho pedagógico realizado e exposto nesta narrativa.

30 porquê desta prática pedagógica

Na tentativa de realizar um trabalho com os estudantes e não para os estudantes, iniciou-se um processo de assembleia a fim de averiguar conhecimentos em língua estrangeira - inglês. A partir destes encontros (3 no total), os estudantes relataram que não tinham condições comunicativas em língua estrangeira e precisavam realizar um trabalho que fosse significativo dentro da formação a que eles se propunham. Assim nasceu a ideia de executar um projeto dentro do letramento para o mundo do trabalho focalizando em uma prática de língua inglesa para fins específicos.

A partir das primeiras aulas, levantaram-se quais eram as necessidades em língua inglesa que permeavam a futura profissão dos estudantes. Assim, o mote central da discussão foi o mundo do trabalho.

A consciência dos estudantes em propor um trabalho era tamanha que em certo momento o questionamento foi: Professor, mas uma aula semanal não é muito pouco? A partir daí, o trabalho pedagógico mediador do professor foi necessário para promover um projeto que pudesse ser executado e ainda levasse em conta a vontade dos educandos.

Seria interessante uma pesquisa mais aprofundada, em que a fala dos alunos viesse à luz, mas nossa proposta aqui é apresentar os resultados que tal prática alcançou.

4 A problemática a ser estudada pelos educandos

Após as conversas com temática voltada ao mundo do trabalho, os estudantes perceberam que precisavam compreender e entender o funcionamento de certos gêneros textuais daquele contexto, os quais seriam de extrema importância em suas vidas profissionais, seja seguindo como técnicos em biotecnologia ou em outras profissões. Assim, eles perceberam que precisavam desenvolver habilidades de escrita e oralidade, focalizando 
seus trabalhos na execução de curriculum vitae e em práticas de entrevistas de emprego. Vale ressaltar que estes estudantes já haviam reforçado que não tinham condições para uma prática comunicativa em língua inglesa.

Assim nasceram a ementa, o conteúdo, os objetivos, as habilidades a serem desenvolvidas, a metodologia de aplicação, os produtos finais e a avaliação do processo. Esses serão agora descritos numa tentativa quase que fotográfica, mesmo em curto espaço. Como os processos eram extremamente dinâmicos, ficará a cargo do leitor desta narrativa inferir como foram os caminhos trilhados (aqueles que não puderam ser expostos nesta narrativa) pelos envolvidos nesta prática a partir do contato com os produtos finais a apresentados.

\section{Ementa ou conteúdo?}

Como se percebeu pela contextualização dos PPCs, a ementa não se baseia em critérios a serem alcançados após os processos pedagógicos, o que temos são apenas conteúdos elencados como se fossem uma profissão de fé a ser buscada pelo estudante. Assim, o que podemos apresentar como ementa é que os estudantes buscaram compreender como funcionava a estrutura de diversos tipos de currículos por meio da comparação de documentos impressos, esses disponibilizados nas primeiras aulas pelo educador. 0 objetivo final era ter condições de escrever um currículo que sanasse a necessidade proposta pelo projeto. Entrevistas de emprego também foram o foco logo na sequência, pois os educandos perceberam que era um gênero ligado ao mundo do trabalho, mas não aqui relatado.

\section{Objetivos}

À maneira ortodoxa da composição de objetivos, em sala traçaram-se alguns horizontes a serem alcançados, como: analisar e compreender a estrutura de currículos; analisar e compreender as ferramentas tecnológicas que envolvem a construção dos currículos; construir currículos. 
7 Metodologia de execução

Após as reuniões para se discutir o tema e o conteúdo/ementa de nossos encontros, deu-se início ao trabalho. O primeiro contato dos estudantes com os currículos se deu por intermédio do educador, o qual trouxe para a sala diferentes currículos (em plataforma impressa), dos quais, em grupos, os estudantes analisaram e descreveram características acerca de layout, tipo de informações, objetividade de informações, relevância dessas e da apresentação geral dos currículos.

Ao terem contato com currículos impressos, os estudantes puderam caracterizar e avaliar aspectos deste tipo de gênero estudado. Duas aulas foram suficientes para tal atividade. Agora era hora da produção.

Aqui aspectos metodológicos muito peculiares saltaram a vista de todos, principalmente do educador, não por subestimar a capacidade dos educandos, mas por aflorarem características que talvez em processos pedagógicos mais ortodoxos pudessem ser negligenciados ou até passados sem serem vistos. Na sequência da escrita, exemplos aparecerão em volume considerável.

Para a confecção dos currículos, optou-se pelo trabalho em meio virtual. Este meio, já muito familiarizado pelos estudantes contemporâneos, ajudou em vários aspectos. Uma metodologia muito explorada foi o uso do Google Classroom7. Nele, era fácil averiguar o andamento dos trabalhos, apresentação desses, mediação remota, dentre outras particularidades.

Para a confecção dos currículos, usaram-se sites especializados, que disponibilizam templates (modelos) que podem ser alterados ao modo do usuário. Esta etapa foi a mais exaustiva devido ao contínuo processo de revisão dos processos, informações, escrita, tradução, tudo com objetivo de alcançar a melhor qualidade possível no trabalho. Desta maneira, já se imagina que foi um trabalho realizado de modo ativo por parte dos estudantes e que não houve sequer um trabalho que não tivesse alcançado um nível satisfatório de produção, ou seja, não houve estudante avaliado como insuficiente (no subtítulo Avaliação, serão descritos como funcionam os conceitos e critérios avaliativos). Complementa-se

\footnotetext{
7 Plataforma criada pela empresa norte-americana Google, a qual cria um ambiente virtual de aprendizagem. Disponível em http://www.classroom.google.com.
} 
àquelas ferramentas, o uso do Google Tradutor e do dicionário online Linguee ${ }^{8}$, ferramentas pelas quais as dificuldades com a língua poderiam ser diminuídas.

A avaliação do processo será descrita após o subtítulo Produtos finais.

\section{Produtos finais}

Aqui serão apresentados alguns dos resultados alcançados e um pequeno parecer/apontamento acerca deles. Não serão apresentados nomes e fotos serão manipuladas quando existentes a fim de resguardar os autores dos trabalhos.

Faz-se necessário revisar qual era a proposta de construção dos currículos. Nesses deveriam constar informações sobre a formação profissional do estudante como foco central, além de informações que trouxessem um panorama sobre aspectos intrínsecos da individualidade de cada um. Não era necessário focalizar a que vaga de emprego ou coisa do tipo se pretendia com o currículo, mas sim dar um horizonte ao leitor sobre as características daquele(a) descrito(a) no currículo. Para além, não se dará ênfase na descrição da totalidade de trabalhos, mas sim de apena 3 exemplos que possam ser explorados na descrição.

\footnotetext{
8 Disponível em https://www.linguee.com/. Este site disponibiliza traduções de textos das mais diferentes esferas do conhecimento e quando um verbete é procurado, a resposta aparece contextualizada.
} 
Exemplo 1:

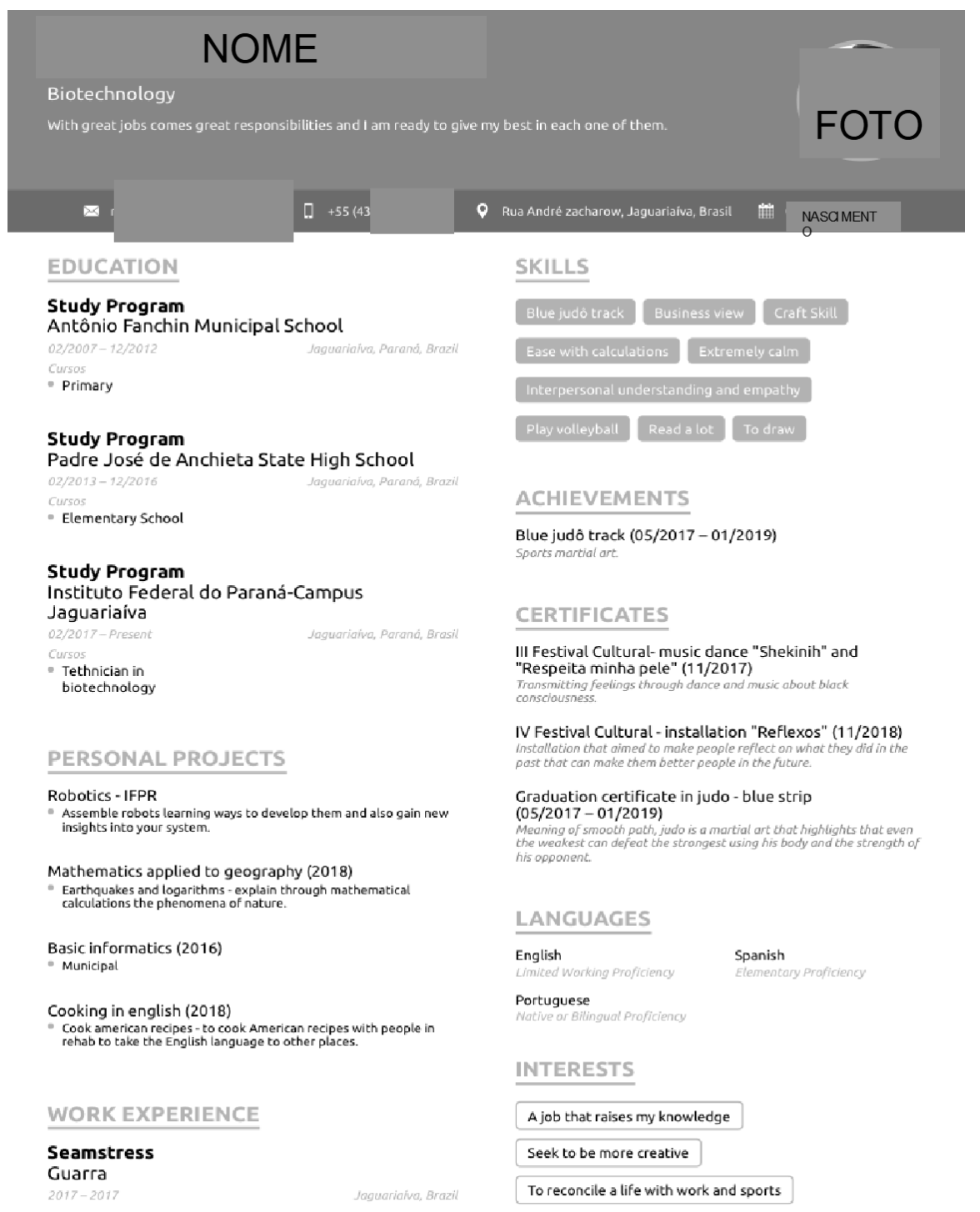

Imagem 1. Curriculum vitae/resume

Fonte: 0 autor.

Acerca do primeiro exemplo, pode-se levantar várias informações sobre os objetivos da proposta e dos caminhos levados até o resultado apresentado. Neste relato, o foco é a apresentação da atividade pedagógica, assim os pormenores desta proposta são facilmente desvendados a partir da observação dos produtos finais. Acerca da estrutura do gênero, valese enfatizar que o uso de plataformas digitais favorece o caminho de construção textual. Percebe-se que o texto possui um layout muito bem organizado, com diferenciação de títulos, subtítulos, divisão em blocos de informações, uso de cores (aqui não expostas) e fontes bem padronizadas. Este exemplo em específico demonstra que o estudante alcançou 
bom nível de resolução dos objetivos propostos para esta prática pedagógica. Quanto ao uso da língua inglesa, percebe-se que as características do gênero currículo, até certo ponto, prescindem de aprofundamento em aspectos de vocabulário bem como de estruturas e períodos que se coordenem para a criação de um sentido com mais complexidade. Reforçase aqui que estes educandos já expuseram, lá no início da proposição, suas condições de comunicação em língua inglesa.

Exemplo 2:

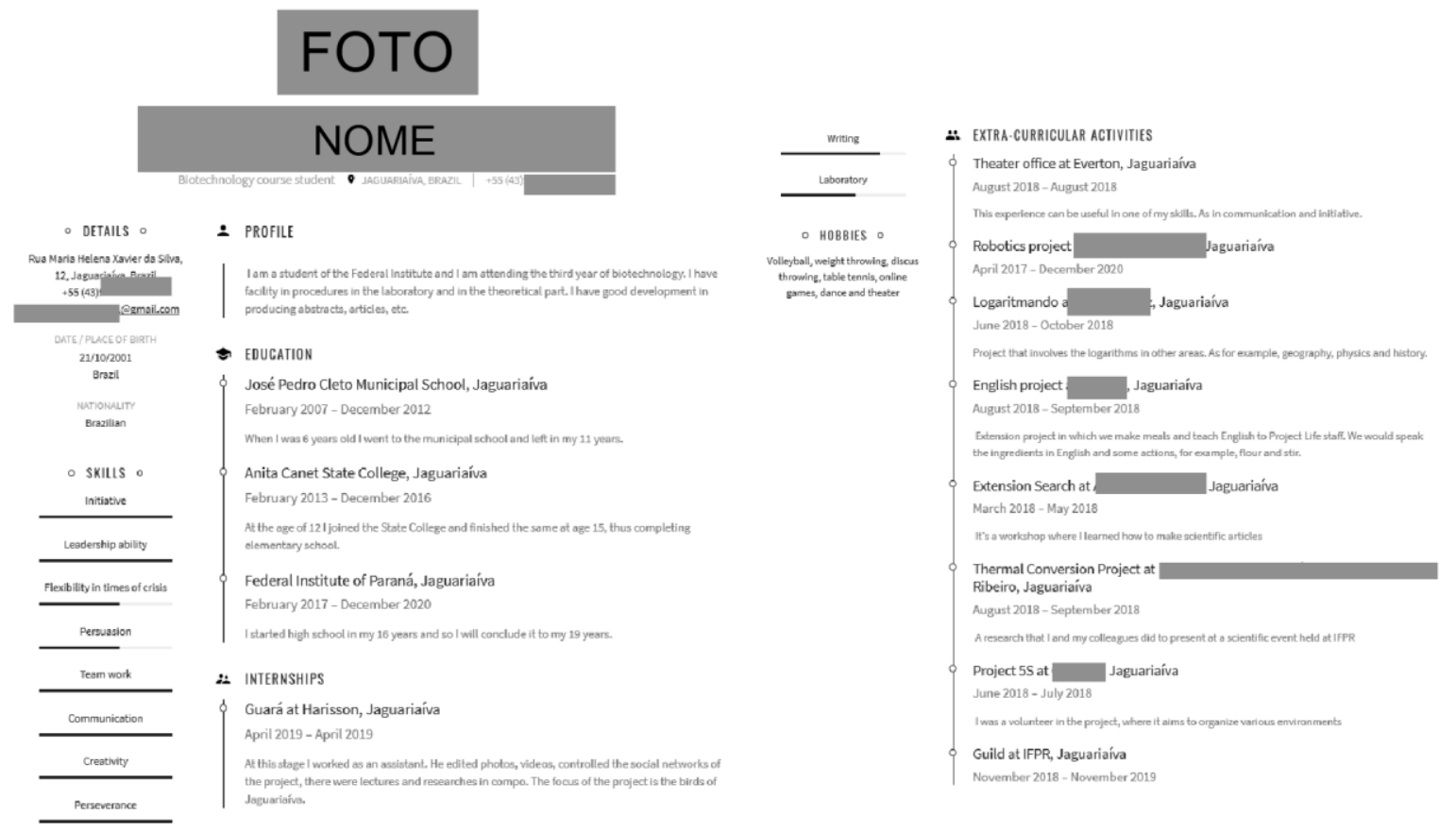

Imagem 2. Curriculum vitae/resume

Fonte: Edição do autor.

De maneira muito particular, o segundo exemplo demonstra um produto final diferente, mas oriundo da mesma proposta. Observa-se que houve uma particular escolha quanto ao layout de apresentação do currículo, uma opção por uso monocromático e organização de informação que deu ênfase às atividades extracurriculares (percebe-se que a mediação do educador poderia ter sido de mais qualidade e mais aprofundada acerca do foco das informações extracurriculares, assim o autor(a) do currículo poderia ter alocado estas informações para um bloco superior, o que anteciparia a informação para o leitor, além de uma revisão linguística mais apurada quanto ao uso da língua inglesa). 
Exemplo 3:

\section{Curriculum Vitae}

Name :
Surname
Date of BIrth :
Place of Birth: Arapoti PR
Age: 16 years
Civil Status: Single
Gender : Masculine
Natlonallty: Brazilan
Address: Altina Jasson Zacharow ;
Number 183
ID Number: 13.431.164-9;Date of
emission 09/12/2011
Naus:
Academlc educatlon
Technical Biotechnology (incomplete)
I intend to take a course in
pharmacology to complement the
biotechnology course

\author{
Professional goal \\ Biotechnology technician: ( I intend to \\ work in this area of work) \\ I'm taking an English course (basic) \\ Vocational Courses \\ Basic Computer (Telecentre Forty \\ hour) \\ Cooking course \\ 5s \\ Personal Presentation \\ I am looking for my first opportunity in \\ the job market. I have total willingness \\ to work in a company and I am willing \\ to work as a team since I am ready for \\ a possible interview.
}

Neste exemplo, percebe-se o quanto a mediação do educador é essencial, e que neste caso, foi deficitária. Observa-se aqui que o educando teve dificuldades em perceber a estrutura do gênero, de adicionar informações pessoais, de percepção da apresentação geral do gênero, dentre outras particularidades.

Para a conclusão de toda a proposta, educador e estudantes utilizaram todo o primeiro semestre do período letivo, ou seja, foram previstos 16 encontros para a realização da prática. 
9 Processos de avaliação

Os processos avaliativos desta proposta visavam mensurar os níveis de apropriação da prática pedagógica a partir de objetivos definidos a cada aula. 0 documento9 que norteia as avaliações do IFPR instrui a avaliação por conceitos, em que $A, B, C$, ou D são categorizados como aprendizagem plena, parcialmente plena, suficiente e insuficiente, respectivamente. Assim, como processo, os estudantes eram avaliados e também avaliavam suas construções durante as aulas e também em trabalho extraclasse. Processos de recuperação previstos nas normativas internas acorreram como preveem os documentos, ou seja, de forma paralela.

10 Tensões/acomodações encontradas

Esta foi a descrição de uma proposta, que avaliada pelo ponto de vista de educador, alcançou um nível satisfatório quanto à execução do trabalho e seus produtos finais. Devese pautar que este processo avaliativo considerou a particularidade de cada estudante (mesmo assim aconteceram casos em que a instrução do educador deveria ter sido de melhor qualidade) e levou em consideração aquilo que já vinha no histórico do estudante. Assim percebeu-se também o quanto o trabalho do educador foi profundo no que diz respeito em diagnosticar os estudantes em suas particularidades e ainda não ser invasivo em conhecer a pessoalidade daqueles.

Quanto às características que mais puderam se observar durante o processo, categorizá-las poderia facilitar o entendimento, por exemplo: Uso da mídia digital - aqui percebeu-se que por mais que a geração dos estudantes seja a que nasceu imersa no uso de tecnologia digital, a dificuldade em usar ferramentas específicas para o trabalho pedagógico foi latente, a exemplo do Google Tradutor (os estudantes apenas executavam o “CTRL C, CTRL V" das expressões do português. Este episódio rendeu um trabalho muito significativo, pois o uso do erro como determinante no melhoramento do trabalho trouxe riquíssimo saber). Uso do português formal - nesta categoria, observou-se que os estudantes tinham a noção

9 Disponível em https://reitoria.ifpr.edu.br/resolucao-no-50-de-14-de-julho-de-2017/. 
de que precisavam usar a língua portuguesa formalmente, mas que aspectos particulares, como a gramática, depreendia um trabalho de pesquisa mais aprofundado. Senso estético neste quesito, muitos estudantes precisavam de mediação a respeito do uso de cores, layout, fontes e ainda na construção de um currículo voltado a um leitor específico. Informações pessoais - observou-se o quanto foi trabalhoso para os educandos falarem de si. Por mais atividades científicas realizadas dentro do Campus diariamente, os estudantes não percebiam que poderiam usar estas informações para enriquecer seus currículos.

Quanto ao aspecto geral da atividade aqui relatada, observa-se que o sistema educacional bancário (FREIRE, 1989) dificulta a prática mais ativa de propostas pedagógicas, mas que devido à liberdade metodológica do corpo docente, há ainda momentos em que atividades mais próximas da realidade dos alunos possam ser trabalhadas de uma maneira significativa. Esta proposta também promoveu situações de ampla reflexão por parte do educador, fazendo-se também parte do processo não como aquele que possui o conhecimento final absoluto, mas como uma pessoa que pode também aprender em um processo que tenha um objetivo humanizador. É latente que processos desta natureza necessitam de momentos de maior reflexão e também levar em consideração os momentos de erro. Por fim, reconsiderar os planejamentos engessados baseados no acúmulo de conteúdos e ementas que se misturam com aqueles se faz necessário para que o trabalho docente seja dinâmico e mais próximo das necessidades do mundo contemporâneo, bem como em projetar o amanhã.

Referências

ARDOINO, J. Abordagem multirreferencial (plural) das situações educativas e formativas. In: BARBOSA, J. G. (coord.). Multirreferencialidade nas ciências sociais e na educação. São Carlos: UFScar, 1998. Disponível em http://www.bibliotekevirtual.org/index.php/2013-0207-03-02-35/2013-02-07-03-0311/469-el/viln18/3836-etnometodologiamultirreferencial-contribuicoes-teorico-epistemologicas-para-a-formacao-do-professorpesquisador.html. Acesso em: 16 de mar. de 2020.

FREIRE, P. Pedagogia do oprimido. Rio de janeiro: Paz e Terra, 1989.

INSTITUTO FEDERAL DO PARANÁ. Projeto Pedagógico do Curso Técnico em Biotecnologia Integrado ao Ensino Médio. Jaguariaíva. 2014. 
Projeto Pedagógico do Curso Técnico em Biotecnologia Integrado ao Ensino Médio. Jaguariaíva. 2017.

MORAN, J. Metodologias Ativas e Modelos Híbridos na Educação. Yaegashi: Novas Tecnologias Digitais: Reflexões sobre mediação, aprendizagem e desenvolvimento23, Curitiba, p.23-37, 2007.

VENTURA, P,C,S. Por uma pedagogia de projetos: uma síntese introdutória. Educ. Tecnol., Belo Horizonte, v.7, n.1, p.36-41, jan./jun. 2002. Disponível em https://seer.dppg.cefetmg.br/index.php/revista-et/article/view/31. Acesso em: 13 de mar. de 2020.

Data de submissão: 20/03/2020. Data de aprovação: 07/05/2020. 